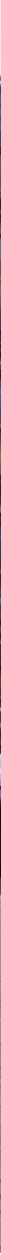

Physical scientists protested against funding reforms with a mock funeral for British science.

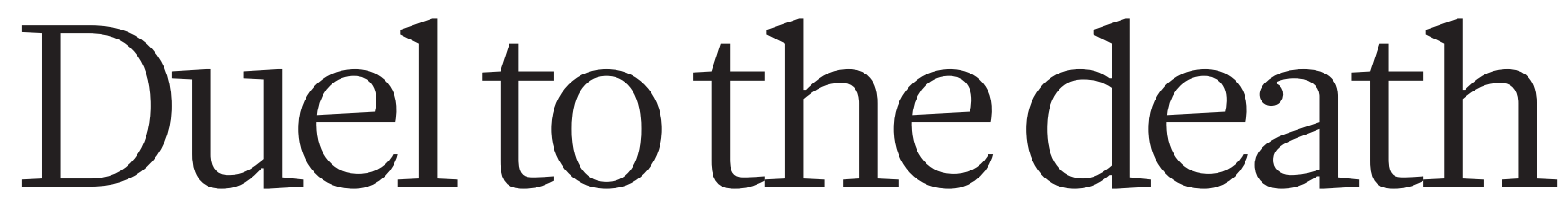

Physicists, chemists and mathematicians in the

United Kingdom are furious about funding reforms that they say threaten blue-skies research.

$\mathrm{T}$ The horse-drawn Victorian hearse canters past Lon-

don's Houses of Parliament and round Parliament Square before trotting smartly down Whitehall. Straggling behind it comes an eclectic mix of scientists, ranging from students with body piercings to tweedjacketed professors. The spectacle makes an odd addition to the spring afternoon traffic, bringing to mind an elegant, if unusual, state funeral.

The truth, however, is much stranger. "We're protesting," explains one $\mathrm{PhD}$ student to a puzzled tourist, "against our research funder."

That funder is the Engineering and Physical Sciences Research Council (EPSRC), the government body that holds the biggest public purse for physics, mathematics and engineering research in the United Kingdom. Facing a growing cash squeeze and pressure from the government to demonstrate the economic benefits of research, in 2009 the council's chief executive, David Delpy, embarked on a series of controversial reforms.

Some were intended to cut the overwhelming number of grant proposals that the EPSRC receives, by limiting resubmissions and temporarily blocking people who submitted too many unsuccessful applications from sending in more. A second set of reforms included requirements that grant applicants explain how their research might generate economic or other benefits, as well as a vigorous overhaul of the EPSRC's research portfolio.

The changes incensed many physical scientists, who protested that the policy to blacklist grant applicants was draconian. They complained that the EPSRC's decision to exert more control over the fields it funds risked sidelining peer review and would favour short-term, applied research over curiosity-driven, blue-skies work in a way that would be detrimental to British science. The souring relationship between the EPSRC and parts of its constituency reached a conspicuously public nadir in May, when 
disaffected researchers launched the 'Science for the Future' campaign with the hearse stunt, which ended by delivering the coffin, signifying the death of British science, and a petition demanding the "immediate reform of the EPSRC's policies" to the prime minister in Downing Street. In a letter to The Daily Telegraph newspaper in support of the protestors, nine Nobel laureates in the United Kingdom and United States accused the EPSRC of "manipulating the process of peer review" and "establishing favouritism schemes".

The battle could be played out elsewhere. Many government funding bodies are facing diminishing budgets in the wake of the global financial crisis, and increasing pressure from politicians to show that the research they are funding will contribute to economic growth. "This is a challenge for research funding agencies across the globe," says Julia Lane, an expert in science policy who formerly worked at the National Science Foundation (NSF) in Arlington, Virginia, and is now a senior managing economist at the American Institutes for Research in Washington DC. "And they're all struggling to provide enough information for policy-makers so that they can keep funding going for basic research."

In Britain, it looks likely that researchers will have to live with this new reality: Delpy and his supporters say that the policies are an unavoidable reaction to a slumping budget and that there will be no U-turns. According to Delpy's detractors, however, the EPSRC provides a lesson in how not to implement such reforms. "They shot themselves in the foot by alienating the community that they're here to serve," says Paul Clarke, a synthetic organic chemist at the University of York, and one of the EPSRC's most vociferous critics.

\section{OPENING ROUND}

The tensions started rising in 2007, shortly after Delpy, a physicist by training, left his post managing the research portfolio at University College London to take command of the EPSRC and its research budget of some $£ 800$ million (US\$1.3 billion). Delpy faced a problem: an overwhelming number of grant applications and a flat budget were starting to push up rejections. In 2008, the success rate for applications dropped from a typical $30 \%$ to $26 \%$ overall and even lower in some fields (see 'Physics of funding'). In March 2009, the EPSRC announced that from the following month researchers could no longer resubmit grant proposals that had been rejected, a policy that has since been implemented at several other UK research councils. At around the same time, it also barred researchers with a record of rejections from sending

in any further funding applications for 12 months - a policy that initially hit more than 200 people.

The changes outraged physical scientists. Within 2 weeks of the blacklisting policy

\section{PHYSICS OF FUNDING}

The UK's main physical-science funder introduced policies o cut grant submissions in 2009 (top), partly in response to a declining budget (bottom)
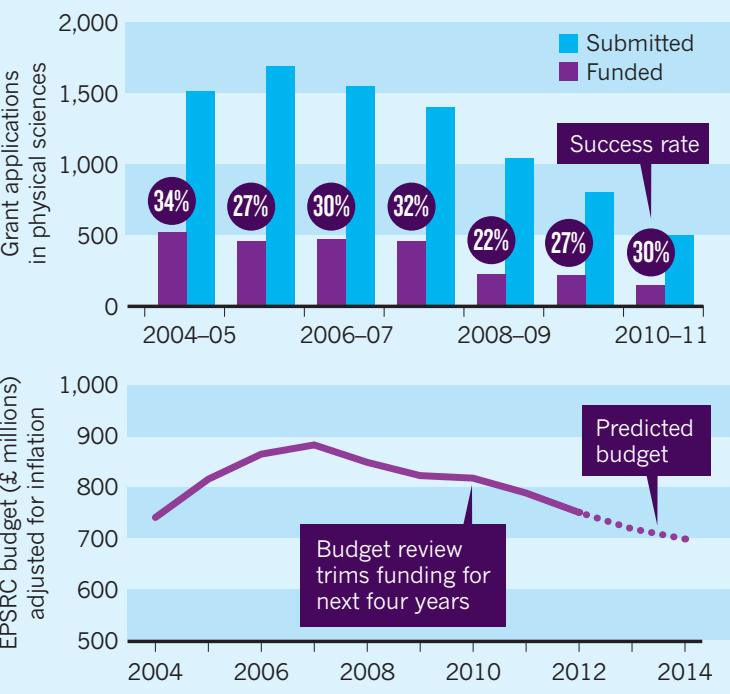

bang for their buck. In 2009, the research councils started to require that funding applicants submit a two-page Pathways to Impact statement, summarizing how they intended to maximize the societal or economic benefits of a project - through commercialization of results, for example, or through public outreach. In November 2011, the EPSRC added a 'national importance' criterion, requiring that researchers describe in a separate statement "the extent to which the research proposed has the potential, over $10-50$ years, to meet national strategic needs".

Similar requirements are already routine at some other funding agencies, such as the NSF, which has asked applicants to explain their proposed project's 'broader impacts' on science and society since 1997 . That requirement has come in for some criticism (see Nature 475, 141; 2011) - but not the level of anger that the new request seemed to inspire in Britain's physical scientists. The impact statements, they said, showed that the EPSRC is inappropriately favouring short-term projects that will have economic benefits. "It is changing the fundamental ethos of research to make it more

being announced, more than 1,200 people had signed an online petition demanding that it be rescinded (see Nature 458, 391; 2009). In May 2009, the EPSRC was forced to water down the policy by delaying its introduction to April 2010, and allowing researchers to apply for one grant during the 12-month 'cooling-off' period. The EPSRC says that only ten researchers are currently blacklisted.

Clarke is one of those ten. Six years ago he concurrently held three EPSRC grants - more than any other researcher at the same career stage. But in January, after submitting a third unsuccessful proposal, he was told that he had been automatically barred from sending in more. Clarke, who works on the chemical origins of life and on synthesizing natural compounds, says that before the EPSRC banned resubmissions, he was able to address critiques of rejected proposals and send them back for re-review - after which they would often be successful. Rather than being a problem, he views the large number of proposals as a sign of scientists with many good ideas, and advocates widening the pool of reviewers by mandating that those who submit EPSRC grants also review a certain number of proposals each year.

The EPSRC was also under growing pressure to demonstrate the impact of its investment in research. This grew out of the 2006 Warry report, Increasing the Economic Impact of Research Councils, as well as subsequent reports, demanding that all the UK research councils show that they are getting the most responsive to the market," says physicist Philip Moriarty of the University of Nottingham, an outspoken critic of the EPSRC reforms. And the national-importance criterion, say some, is simply asking for the impossible. "It's very hard to justify the economic importance of work that might not become applicable to realworld problems for decades," says postdoctoral mathematician Will Merry at the University of Cambridge, UK. (Merry's research problem, how to solve the motions of three or more interacting bodies, was first set out by Isaac Newton in 1687 - suggesting that science sometimes has to take the long road.)

Martin Rees, former president of the Royal Society in London and a cosmologist at the University of Cambridge, says he worries that the new requirements could affect how young researchers apply for their first grant. "It's going to make them slant their application in a way that might not be optimal from the point of view of the research," he says. The council should focus on making sure that the "brightest people don't get discouraged", adds Rees, who says he finds the idea of asking researchers to write about the potential future national importance of their work "absurd".

But the EPSRC had more reforms up its sleeve. In July 2011, it published the first of three phases in its Shaping Capability strategy, which divided the organization's research portfolio into more than 100 fields, with the aim of maintaining or expanding areas of national importance and excellence, such as catalysis and energy storage, and shrinking others such 
as mathematical physics and mobile computing. The council revealed that future postdocs and other fellowships would be funded only in areas that were in line with the strategy; at the outset, for example, mathematics postdocs would be funded only in statistics and applied probability.

To the critics, that decision was further evidence that the council ranked short-term pay-off above blue-skies research, in this case favouring the needs of the City, London's large financial sector, which is hungry for statistical expertise. The policy had an immediate impact for Merry, who finished a 12-month EPSRC doctoral-prize fellowship and struggled to find a postdoc at home. He is now set to start one at ETH Zurich in September. Merry says that all the maths $\mathrm{PhD}$ students he knows at the University of Cambridge are following a similar path. "The most visible outcome of the change in funding is that to the best of my knowledge they're all going abroad next year," he says.

Some researchers also have a broader concern: that EPSRC administrators are taking over the role of working scientists in deciding how money should be spent and, as a consequence, are funding mediocre research in arbitrarily selected areas. Instead, they say, the EPSRC should focus on supporting the best-quality science in any area of its remit, as judged by peer review. "Non-scientists are making decisions that impact on the future spend of science money - and that is wrong," says Tony Barrett, a synthetic organic chemist at Imperial College London and one of the organizers of the Science for the Future campaign. "They are not qualified to make those decisions."

The uproar over impact and national importance grew so loud that, in November 2011, the House of Lords Science and Technology Committee held a session to discuss the policies with Delpy and civil engineer John Armitt, then the council's chair. The EPSRC also agreed to further discussions with the scientific community before rolling out the final phase of the Shaping Capability strategy, which it did in March 2012. The announcement, which filled in funding details for just over 50 fields, met a frosty, but somewhat less angry, reception.

\section{MAKING IMPACT}

Delpy stoutly defends his organization and its reforms. The policies to cut grant applications have worked, he says: the success rates for applications are back up to around 30-35\% - "a healthy level of competition".

He rejects the criticisms of the impact and national-importance strategies. The focus on economic impacts is nothing new, he says, nor does it come from his own experience in applied bioengineering. (He developed techniques for monitoring premature babies.) The 1994 royal charter that officially established

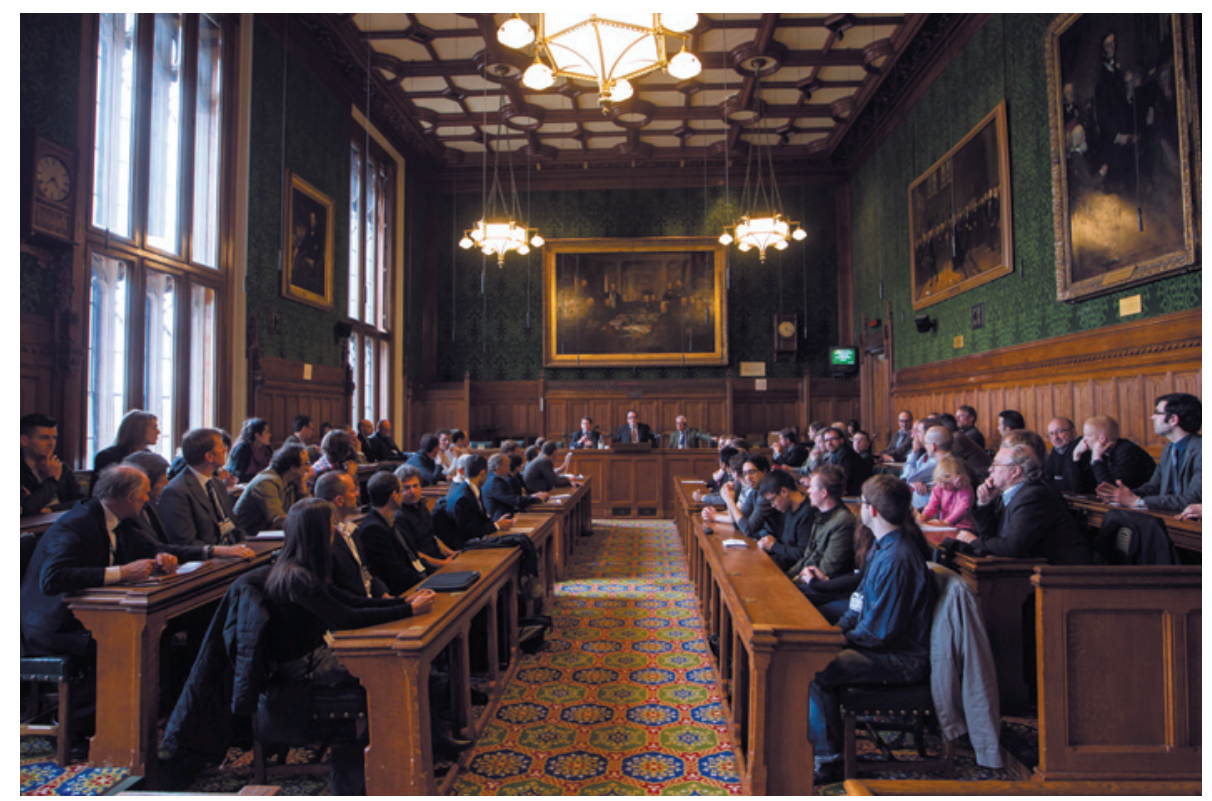

In May, physical scientists called for research-council reform at the House of Commons in London.

the EPSRC states that contributing to the country's economic competitiveness is one of the body's three main aims. The prominence placed on it in recent years is largely the result of government pressure, Delpy says. "You must realize that the term 'economic impact' was something that was imposed on us by the Treasury." What's more, the EPSRC does not expect a precise forecast of what impacts a research proposal could have decades down the line, he says; rather, researchers are encouraged to describe how any impacts that they can foresee might be speedily achieved.

Delpy maintains that peer review is paramount at the agency. The decision to limit the EPSRC's maths postdocs to statistics was based on an independent international review of maths commissioned by the council and published in 2010, which singled out the field as an area of serious concern. "We decided we had to do something to get new blood into statistics," he says. "This is not a response to government or the call of the City." Mathematicians can turn to the Royal Society or the Leverhulme Trust in London for funding, he points out. And although the research council's budget is set to decline - by $6 \%$ in cash terms between 2010-11 and 2014-15he says that the proportion of funding going to discovery-led or blue-skies research has stayed roughly flat at around $50-60 \%$ of the total. "Where's the evidence the system is broken?" he asks.

Delpy does regret the rift that the reforms have opened up between the council and researchers. "Of course we could have done things better," he concedes, particularly in communicating what the council was doing and why. "I would have liked to have been able to carry the community with me and have everyone feel that they were engaged." At the same time, he says, "if you change any of the ways of working you are going to create some degree of upset".

Britt Holbrook, a philosopher at the University of North Texas in Denton, who specializes in science policy, says that the EPSRC's biggest mistake lay in banning resubmissions and blacklisting researchers. "It's totally understandable that did not go down well," he says. "If you stop people from resubmitting, that cuts out a large part of the value of peer review." But Holbrook, who co-authored an influential review of the NSF's broaderimpacts criterion, says that the critics are fighting a losing battle against the impact agenda. "People are working against the political and economic realities," he warns, and would be better off trying to shape the drive for impact, rather than block it.

The hearse parked outside Downing Street, however, suggests that this advice is falling on deaf ears; the organizers of Science for the Future say that they are planning further protests over the summer. And Delpy's critics have little time for his explanations, saying, for example, that they are sceptical of EPSRC figures showing no decline in blue-skies research, given that the council defines the term itself. Clarke prefers to point to figures showing that in 2010-11, the EPSRC funded 151 proposals in the physical sciences, excluding engineering, down from more than 500 in 2004-05. Yet there are more than 3,000 scientists in the United Kingdom who are eligible to apply for EPSRC funding.

"People would rather not submit than submit, get blacklisted and hence be seen as a failing academic by their department," says Clarke. "There is now a culture of fear in academic departments."

Ananyo Bhattacharya is Nature's chief online editor. 